\title{
Are Socio-Demographic Factors Associated to Burnout Syndrome in Police Officers? A Correlational Meta-Analysis
}

\author{
Raimundo Aguayo*, Cristina Vargas, Gustavo R. Cañadas, and Emilia I. De la Fuente
}

University of Granada (Spain)

\begin{abstract}
Título: ¿Están los factores sociodemográficos asociados al síndrome de burnout en policias? Un meta-análisis correlacional.

Resumen: El síndrome de burnout se considera una reacción al estrés crónico que se ha observado principalmente en profesionales que trabajan de cara a otras personas. Las características sociodemográficas pueden afectar al desarrollo del síndrome, aunque los resultados obtenidos en los estudios empíricos han sido contradictorios. El objetivo del presente estudio es realizar una revisión meta-analítica sobre cuatro factores sociodemográficos (edad, sexo, estado civil y número de hijos) que pueden estar correlacionados con las dimensiones del Maslach Burnout Inventory (cansancio emocional, despersonalización y realización personal) en policías. Estos profesionales han sido considerados como un grupo de riesgo para desarrollar el síndrome debido a las características de su trabajo. Se obtuvieron 43 estudios empíricos que cumplían con los criterios de inclusión: 23 para edad, 32 para sexo, 9 para estado civil y 4 para número de hijos. Se utilizó el coeficiente de correlación bivariada como métrica del tamaño del efecto. Los resultados mostraron que todos los tamaños del efecto medio fueron bajos y la mayoría de ellos estadísticamente no significativos. Muchos de los estudios empíricos no informaban de suficiente información estadística para estimar los tamaños del efecto medio. Esta falta sistemática de información puede estar contribuyendo a que se sigan encontrando resultados contradictorios.

Palabras clave: MBI; burnout; policías; factores sociodemográficos; metaanálisis.
\end{abstract}

\section{Introduction}

Burnout syndrome is a problem that affects a wide range of professions. It is characterized by symptoms that appear when workers suffer from chronic stress. At particularly high risk are workers whose jobs involve direct contact with the public, for example, nurses, doctors, teachers, and police officers (Leiter, Bakker \& Maslach, 2014). At present, police work is one of the most stressful occupations in the world (Vuorensyrjä \& Mälkiä, 2011). Police officers are subjected to a variety of potential stressors, which include pressure from superiors, social perceptions of their work, as well as exposure to violent events that can have a negative physical and psychological impact on their lives (BacktemanErlanson, Padyab \& Brulin, 2012). Previous research has detected high stress levels in police officers (e.g., Durán, Montalbán \& Stangeland, 2006; De la Fuente, Aguayo, Vargas \& Cañadas, 2013), which even surpass those found in other groups of professionals (e.g., Backteman-Erlanson et al., 2012). For this reason, police officers are regarded as being at a high risk of developing the burnout syndrome.

Burnout is generally conceived as having three dimensions: (i) emotional exhaustion (EE) refers to sensations of

* Correspondence address [Dirección para correspondencia]:

Raimundo Aguayo, Department of Social Psychology, University of Granada (Campus Melilla), C\Santander, $n^{\circ} 1$ 52071, Melilla (Spain). E-mail: raguayo@ugr.es

\begin{abstract}
Burnout is considered a long term stress reaction which is seen primarily among professionals who work face-to-face with other people. Socio-demographic characteristics have been suggested as risk factors to its development, although empirical studies have yield contradictory results. The objective of this study is to conduct a meta-analysis of four sociodemographic factors (age, sex, marital status, and number of children) that may be correlated to the Maslach Burnout Inventory dimensions (emotional exhaustion, depersonalization, and personal accomplishment) in police officers. These professionals have been considered a high-risk occupational group to suffer burnout due to specific characteristics of their job. We collected 43 empirical studies that fulfilled the inclusion criteria: 23 on age, 32 on sex, 9 on marital status, and 4 on number of children. The bivariate correlation coefficient was used as the effect size measure. The results show that all the average effect were small, and the majority of them were not statistically significant. We can conclude that sex and age are factors to discard in the development of the burnout in police officers. We found that many studies did not report enough statistical information to estimate effect sizes. This systematic lack of information is likely to contribute finding contradictory results.

Key words: MBI; Burnout; police; socio-demographic factors; metaanalysis.
\end{abstract} continuous interactions with other workers and clients; (ii) depersonalization (D) is the development of negative and cynical attitudes about one's clients; (iii) reduced personal accomplishment (PA) reflects the tendency of workers to feel unhappy about themselves and dissatisfied with their professional achievements (Maslach \& Jackson, 1981). It is frequent for professionals with burnout syndrome to also suffer from physical health problems (e.g. psychosomatic illnesses), emotional disorders (e.g. depression and anxiety), and workplace problems (e.g. absenteeism and job dissatisfaction).

Although it is not the only tool available, the Maslach Burnout Inventory (MBI; Maslach \& Jackson, 1981) is now considered to be the "gold standard" for measuring the burnout, which includes the three dimensions of the syndrome and has been used to conceptualize as well as to evaluate the syndrome (De la Fuente et al., 2013). The MBI is the most used instrument for measuring burnout (Schaufeli, Leiter \& Maslach, 2009; Worley, Vassar, Wheeler \& Barnes, 2008). Moreover, according to Schaufeli and Enzmann (1998) over $90 \%$ of burnout research is done with the MBI.

There is a wide range of literature on the risk factors that favor the appearance and subsequent development of the burnout syndrome. Up until now, research has largely focused on psychological and occupational risk factors though most studies also mention socio-demographic variables. In regards to police officers, the analysis of these variables has 
led to inconclusive and often contradictory results. As a result, there is currently no consensus as to which of these variables are conducive to the development of burnout syndrome.

For example, it is not clear whether younger police officers are at a greater risk of burnout than older ones (Aranda \& Pando, 2010). Nor is there conclusive evidence that being in a sentimental relationship or having children protects officers against burnout (Durán et al., 2006). In relation to sex, certain studies affirm that female officers are more prone to emotional exhaustion (e.g., Adebayo, Sunmola \& Udegbe, 2008) whereas male police officers are more susceptible to depersonalisation (e.g., Burke \& Mikkelsen, 2005). However, according to other works, the relation between these two variables is not statistically significant (e.g., Chrisopoulos, Dollard, Winefield \& Dormann, 2010; McCarty, Zhao \& Garland, 2007).

The role that socio-demographic factors play in the development of the burnout syndrome is important for several reasons: first, it is important to check if these factors have a direct influence on burnout levels and its significance. This will allow the elaboration of a risk profile of police workers suffering burnout; second, the identification of several risk factors that may define a risk profile would facilitate the development of primary and secondary intervention programs. These programs focus their actions on preventing the syndrome in general or on risk population, and so, they are generally preferable than tertiary programs that are centered on recovering workers from health damages; Third, explicative models can be tested and elaborated for this specific population depending on the relations of socio-demographic factors on the three dimensions of burnout.

For this reason, certain authors (e.g., Salazar, 2015) highlight the need for meta-analytic studies that can shed light on the role of these risk factors. Specific questions are still waiting to be answered including the magnitude of the relations between socio-demographic factors and burnout, its variability, and which moderators can explain this variability. However, to our knowledge, there are no meta-analytic reviews that specifically focus on police officers. This is an excellent reason for analyzing the role of socio-demographic variables in the development of the burnout syndrome. Only in this way can they be confirmed or excluded as risk factors for this group of professionals.

The objective of this research was to carry out a metaanalytic review (Ato, López \& Benavente, 2013) of four socio-demographic variables (age, sex, marital status, and number of children) which could be potentially related to the appearance and development of one of the three burnout dimensions, measured with the MBI, in police officers. This meta-analysis was done following the recommendations of PRISMA statement (Moher et al., 2015).

\section{Method}

\section{Literature review and inclusion criteria}

Various search strategies were used to identify primary studies. Firstly, we searched the following electronic databases: Web of Science, Scopus, OVID, Proquest, SocIndex, CSIC-ISOC, Dialnet, Psicodoc, and Social Science Research Network. The key words used were ("Maslach Burnout Inventory" or "MBI") and ("police*” or "officer?"). Secondly, previous reviews and meta-analytical studies along with their references were consulted. Thirdly, a search was made in scientific journals related to the topic. In addition, Google Scholar, Proquest Dissertations and Theses, and TESEO database were consulted. The Science Citation Index was also accessed to find studies that cited the work thus identified. Finally, references of the selected research were also retrieved and selected. The literature search was finished in June 2016, using default parameters.

Three inclusion criteria were used in this meta-analysis. All studies were empirical research that applied the Maslach Burnout Inventory (MBI) to a sample population of police officers and measured at least one socio-demographic variable. They all included sufficient statistical information to calculate the effect size between one of the MBI dimensions and at least one of the socio-demographic variables. Finally, all publications were written in English, Spanish, Portuguese, Italian, or French because these were the languages spoken by the authors of this study.

The search was limited to the MBI because it is the most used instrument among researchers. Over $90 \%$ of studies used the MBI, according to Schaufeli and Enzmann (1998). Moreover, there is no other instrument that fit the tridimensional conceptualization better than the MBI. For example, the Oldenburg Burnout Inventory (Halbesleben \& Demerouti, 2005) only measures two dimensions (exhaustion and disengagement) and the Copenhagen Burnout Inventory (Kristensen, Borritz, Villadsen \& Christensen, 2005) equals the burnout syndrome to emotional exhaustion, not considering the other two dimensions.

The complete search produced 1,133 published and unpublished articles, book chapters, master theses, $\mathrm{PhD}$ dissertations, and conference papers. Of these documents, 213 were of potential interest, based on their title and abstract. After a more detailed reading of these studies, 43 were found to fulfill all of the inclusion criteria. More specifically, the number of studies that focused on age, sex, marital status, and number of children was $23(n=6,276), 32(n=$ $19,655), 9(n=2,659)$, and $4(n=1,143)$, respectively. The list of included studies is available upon request to authors. It is noteworthy that although the variables were measured in most cases, only $49 \%$ of the remaining studies included sufficient statistical information to calculate an effect size (see Figure 1). 

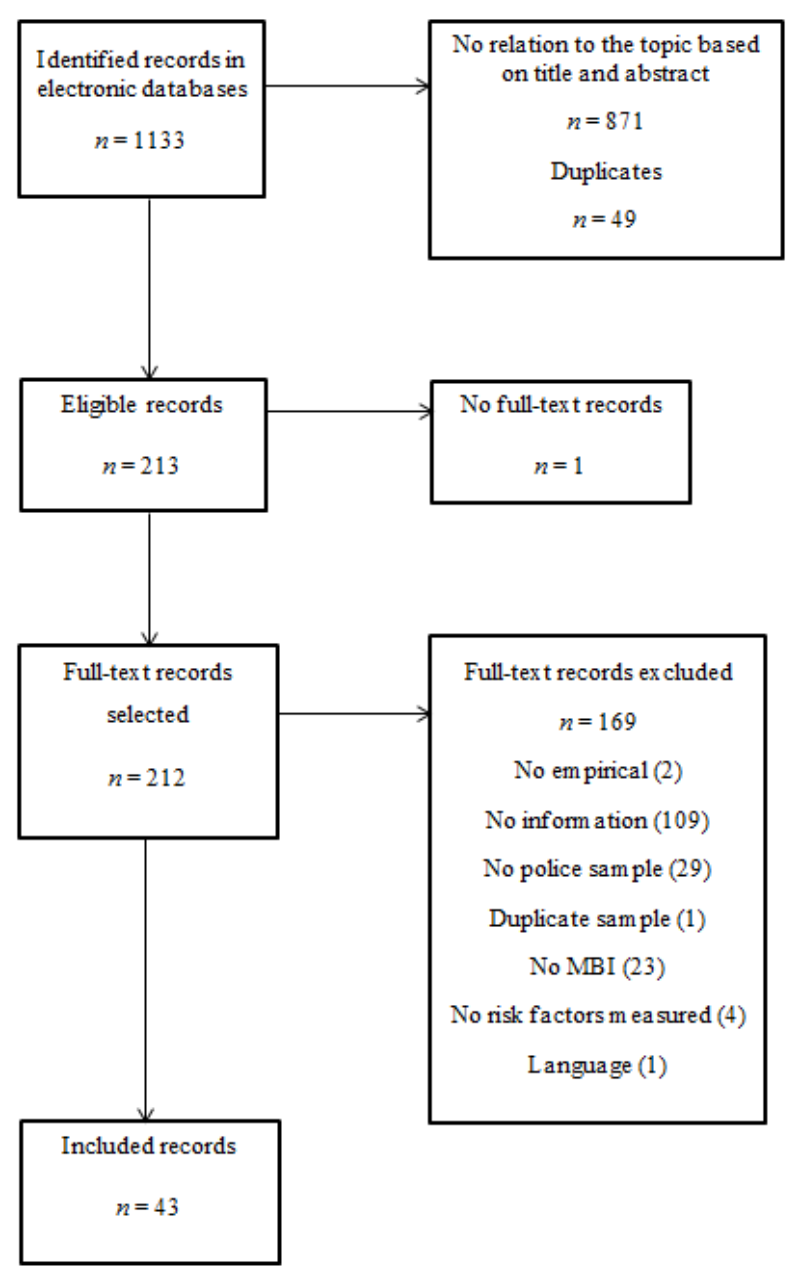

Figure 1. Flow chart of studies included in the meta-analysis.

\section{Coding of variables and calculation of effect size}

In order to analyze the variables that could be correlated with the effect sizes for each study, several substantive, methodological, and extrinsic variables of the primary studies were coded (Sánchez-Meca \& Botella, 2010). For greater objectivity a codebook, available upon request, was created with the coding norms of these moderator variables.

Substantive variables were the following: (a) age (mean value and standard deviation of the age of the sample); (b) sex (percentage of males in the sample); (c) marital status (percentage of unmarried subjects); (d) children (percentage of subjects with children); (e) job seniority (mean value and standard deviation of the length of time that the subjects had been working at their current post); (f) professional experience (mean value and standard deviation of the length of time that the subjects had been working in their profession); (g) rank (percentage of subjects belonging to the lowest police rank); (h) work type (percentage of subjects who worked as patrol officers); (i) shift (percentage of subjects on a rotating shift); (j) socio-economic status (percentage of subjects of low socio-economic status); (k) education level (percent- age of subjects with a low education level).

The methodological variables were the following: (a) sample size; (b) Cronbach's alpha coefficient of each of the MBI dimensions; (c) MBI type (1, original; 2, adaptation); (d) MBI version (1, HSS; 2, GS); (e) MBI language (1, English; 2, Spanish; 3, other); ( $\mathrm{f}$ ) number of items in each MBI dimension; (g) design (1, experimental; 2, quasi-experimental; 3 , ex post facto; 4, survey; 5 , observational); (h) measurement strategy (1, cross-sectional; 2, longitudinal); (i) sampling method (1, probabilistic; 2 , non-probabilistic); (j) response rate.

The extrinsic variables were the following: (a) publication type $(1$, article included in a journal with a JCR impact factor; 2, article in a journal without a JCR impact factor; 3, Master thesis or $\mathrm{PhD}$ dissertation; 4, other type of document); (b) location where the study was conducted; (c) year of publication.

Correlation coefficients were used as the effect size index between each of the burnout dimensions and the sociodemographic factors of age, sex $(0=$ female; $1=$ male $)$, marital status $(0=$ not married; $1=$ married $)$, and number of children gender, this index was chosen following the recommendations by Rosenthal (1991). When bivariate Pearson correlations could not be directly obtained from primary studies, mean values, standard deviations, sample sizes, and $t$-values were used to estimate the effect size (Cooper, Hedges \& Valentine, 2009).

The coding process was evaluated on the basis of a random sample $(20 \%)$ of the meta-analyzed studies. Two independent judges, who were not directly involved in the research, were asked to code this subset. The level of coding reliability thus obtained was found to be highly satisfactory. In the case of continuous variables, the average intraclass correlation was 0.78 (minimum $=.71$, maximum $=1$ ). For qualitative variables, the average Cohen's kappa was 0.84 (minimum $=.78$, maximum $=1$ ). When the effect size calculations were subjected to reliability analysis, they produced an average intraclass correlation coefficient of 0.85 (minimum $=.76$, maximum $=1$ ) between the estimates made by the two independent judges.

\section{Statistical analysis}

For meta-analytic calculations, Pearson correlation coefficients were converted to Fisher z scores in order to improve the normality of the distributions (Cooper et al., 2009). They were then transformed back into correlation coefficients since this facilitated the interpretation of results. Normality assumption and influential cases were tested with qqplots, the Shapiro-Wilk test and Cook's distance.

To avoid problems of statistical dependence, separate meta-analyses were performed for three of the four selected outcomes and the four MBI dimensions. Each analysis calculated the mean effect size with $95 \%$ confidence intervals, the $Q$ test for heterogeneity, and the $I^{2}$ index (Higgins \& Thompson, 2002; Huedo-Medina, Sánchez-Meca, Marín- 
Martínez \& Botella, 2006). When the heterogeneity was greater than expected, a moderator analysis was performed using ANOVAs for qualitative moderator variables and regression models for continuous moderator variables, all by weighted least squares (Cooper et al., 2009). Also multiple regression models were performed to test the influence of several moderators together.

For age and sex variables, a random-effects model was applied since it is generally considered to be more realistic than the fixed-effects model for this type of data (Card, 2012). In contrast, a fixed-effects model was adopted for marital status and number of children because of the scarcity of studies detected. Publication bias was assessed through Egger regression test and the rank correlation test. The statistical analyses were performed with the software applications Comprehensive Meta-Analysis 3.0 (Borenstein, Hedges, Higgins \& Rothstein, 2014) and the R 3.1.1 metafor package (Viechtbauer, 2010).

\section{Correlation's distribution among $\mathrm{EE}$ and age}

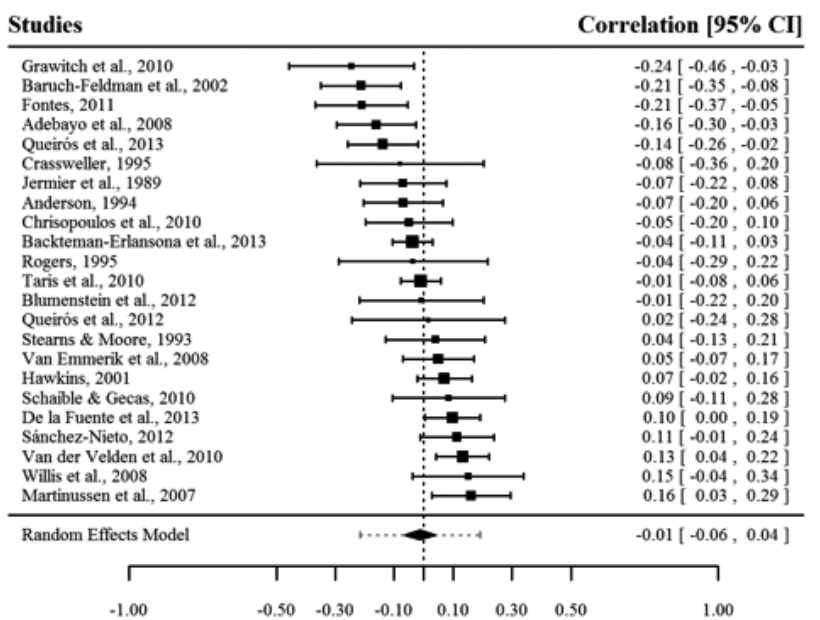

Correlation's distribution among $\mathbf{E E}$ and marital status

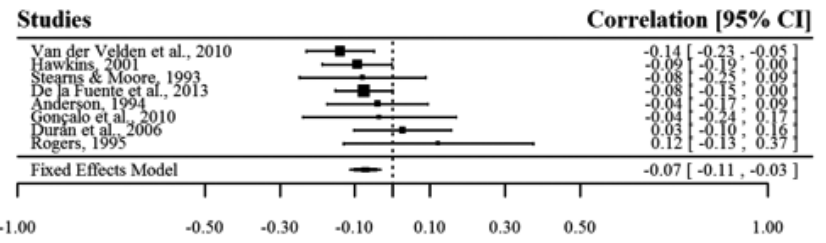

Figure 2. Forest plots of socio-demographic variables in emotional exhaustion.

\section{Results}

\section{Distribution of effect sizes}

Before analyzing the average effect sizes, an exploratory analysis was conducted in order to check normality and influential cases. Since the study of Adebayo et al. (2008) was identified as an outlier, it was not used to calculate the average correlation between Emotional Exhaustion and sex. Likewise, Briones and Boutin (2013) study was eliminated from the distribution of correlation coefficients among Emotional Exhaustion and marital status. The normality assumption was met in all datasets, except for the correlation coefficients between Personal Accomplishment and age. However, visual inspection of the data revealed a very slight departure from normality.

The first purpose of a meta-analytic study is to describe the distribution of effect sizes (see Figures 2, 3, and 4) and estimate the average effect size. The results of this study are presented for each MBI dimension: Emotional Exhaustion (EE), Depersonalization (D), and Personal Accomplishment (PA). Other complementary data (forest plots, funnel plots, correlation matrix between variables, is available upon request to the corresponding author).

\section{Correlation's distribution among EE and sex}

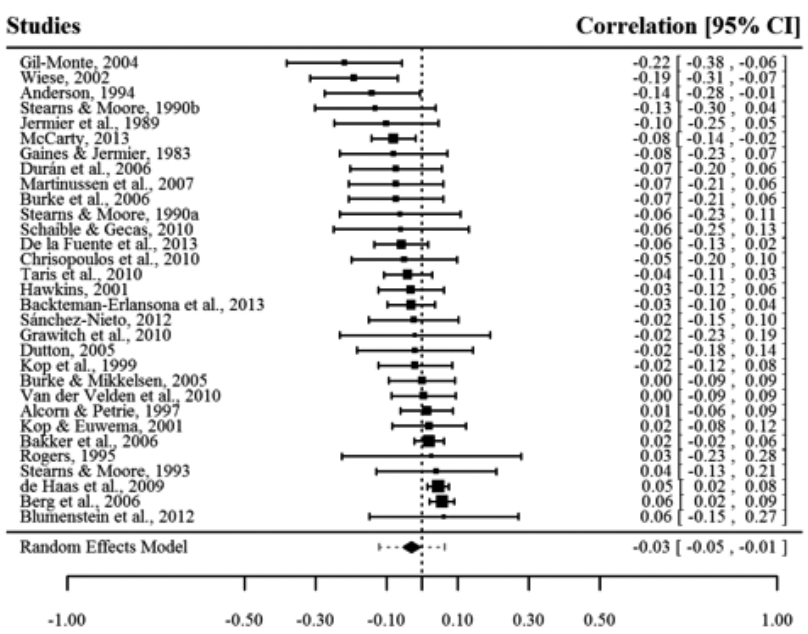

Correlation's distribution among EE and children

Studies Correlation $[95 \% \mathrm{CI}]$

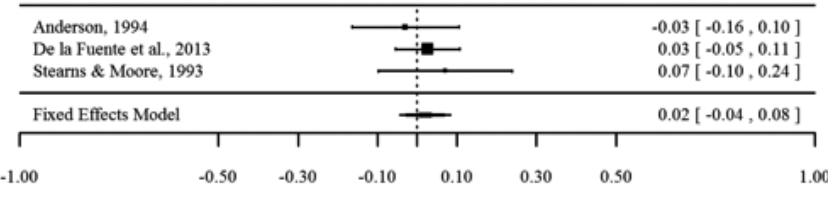


Correlation's distribution among $D$ and age

\begin{tabular}{ll} 
Studies & Correlation [95\% CI] \\
\hline Anderson, 1994 \\
Backteman-Erlansona et al., 2013 \\
Hawkins, 2001 \\
Queirós et al, 2013 \\
Van Emmerik et al., 2008 \\
Queirós et al., 2012 \\
Stearns \& Moore, 1993 \\
Schaible \& Gecas, 2010 \\
Crassweller, 1995 \\
Richardsen et al., 2006 \\
Sánchez-Nieto, 2012 \\
De la Fuente et al., 2013 \\
Fontes, 2011 \\
Martinussen et al, 2007 \\
Willis et al., 2008
\end{tabular}

Correlation's distribution among $D$ and marital status

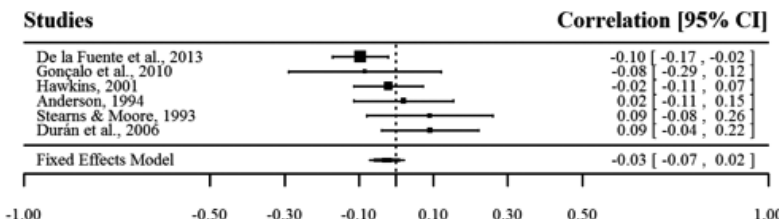

Figure 3. Forest plots of socio-demographic variables in depersonalization.
Correlation's distribution among $\mathrm{PA}$ and age

\section{Studies}

\begin{tabular}{l} 
Studies \\
\hline De la Fuente et al., 2013 \\
Martinussen et al., 2007 \\
Sánchez-Nieto, 2012 \\
Anderson, 1994 \\
Stearns \& Moore, 1993 \\
Richardsen et al., 2006 \\
Queirós et al., 2012 \\
Hawkins, 2001 \\
Colegrove, 1983 \\
Taris et al., 2010 \\
Queirós et al., 2013 \\
Schaible \& Gecas, 2010 \\
Van Emmerik et al., 2008 \\
Willis et al., 2008 \\
Fontes, 2011 \\
Crassweller, 1995
\end{tabular}

Correlation's distribution among PA and marital status
Correlation's distribution among $D$ and sex

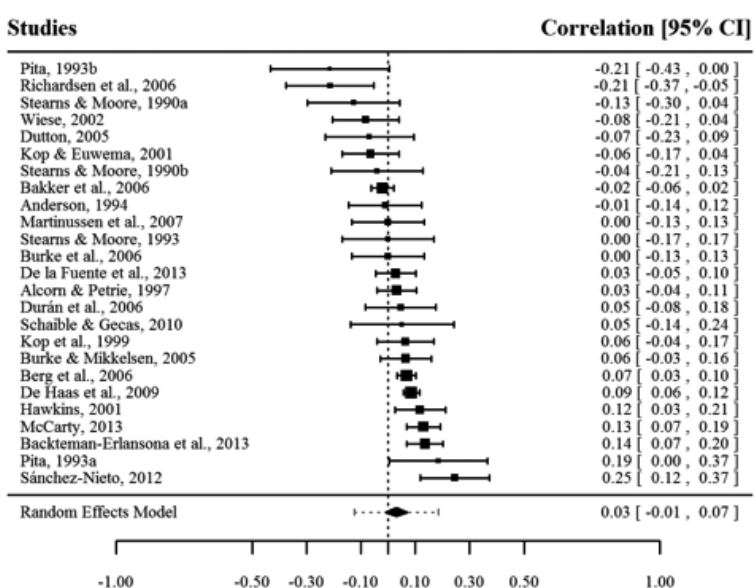

Correlation's distribution among D and children

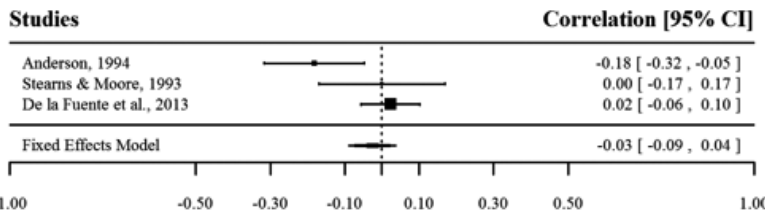

\section{Correlation's distribution among PA and sex}

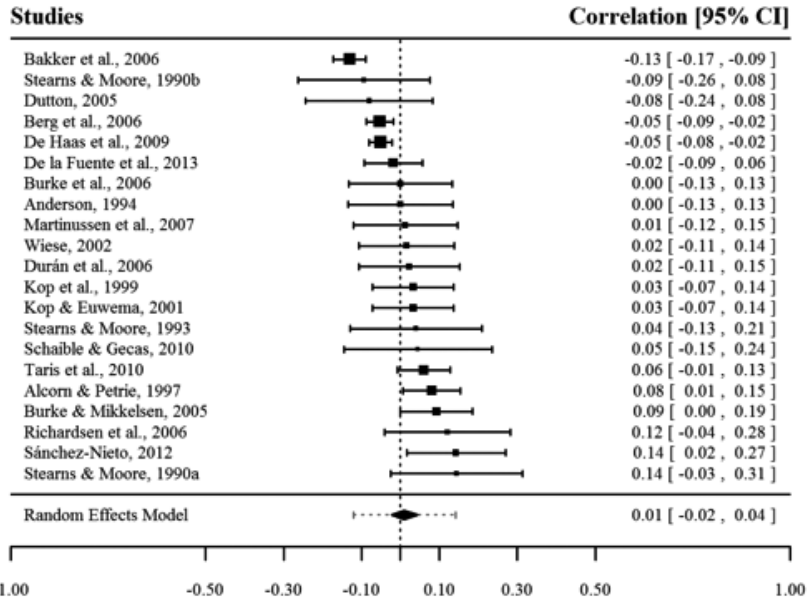

\section{Correlation's distribution among PA and children}

\begin{tabular}{|c|c|c|c|c|c|}
\hline Studies & & & & & Correlation $[95 \% \mathrm{CI}]$ \\
\hline $\begin{array}{l}\text { Stearns \& Moore, } 1993 \\
\text { Durain et al., 2006 } \\
\text { De la Fuente et al., } 2013 \\
\text { Briones \& Kinkead, } 2013 \\
\text { Anderson, } 1994\end{array}$ & & & 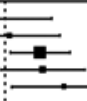 & & $\left.\begin{array}{r}-0.05 \\
0.01 \\
0.0 .22,0.12 \\
0.09 \\
0.10 \\
0.01,0.14 \\
0.15 \\
0.01 \\
0.02,0.20 \\
0.02 \\
0.29\end{array}\right]$ \\
\hline Fixed Effects Model & & & - & & $0.08[0.03,0.13]$ \\
\hline$T$ & $T$ & $T$ & $T$ & $T$ & $T$ \\
\hline-0.50 & -0.30 & -0.10 & 0.10 & 0.30 & 0.50 \\
\hline
\end{tabular}

Figure 4. Forest plots of socio-demographic variables in personal accomplishment.
Correlation $[95 \% \mathrm{CI}]$

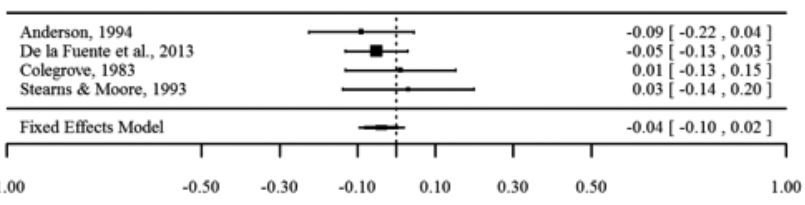


In regards to $\mathrm{EE}$, the following mean correlation coefficients were obtained: age, -.01 (95\% CI: $-.06, .04 ; k=23)$; sex, -.03 (95\% CI: $-.05,-.01 ; k=31)$; marital status, -.07 (95\% CI: -.11, -.03; $k=8)$; number of children, .02 (95\% CI: $-.04, .08 ; k=3)$.

In reference to $\mathrm{D}$, mean correlation coefficients were: age, -.06 (95\% CI: -.11, -.01; $k=15$ ); sex, .03 (95\% CI: -.01, $.07 ; k=25)$; marital status, -.03 (95\% CI: $-.07, .02 ; k=6)$; number of children, -.03 (95\% CI: -.09, .04, $k=3$ ).

In the case of PA, the mean correlations coefficients were the following: age, .02 (95\% CI: $-.03, .08$; $k=16)$; sex, .01 (95\% CI: -.02, .04; $k=21)$; marital status, .08 (95\% CI: $.03, .13$; $k=5$ ); number of children, -.04 (95\% CI: -.10, .02, $k=4)$.

Based on Cohen's (1988) cut-off points, all mean effect sizes were small, and the majority of them were not statistically significant. Nevertheless, the mean correlations between EE and sex, EE and marital status, D and age, and PA and marital status were statistically significant. Despite the inclusion of unpublished studies (e.g. Master theses and PhD dissertations), publication bias was statistically tested. The Egger regression test showed statistically significant results for the effect sizes of sex and $\mathrm{EE}(p<.001)$, and sex and PA $(p=.004)$. The rank correlation test was then applied, but showed no evidence of bias. These results indicated that publication bias was unlikely to seriously affect our findings.

The second purpose of a meta-analysis is to estimate the heterogeneity of the mean effect size. For marital status and number of children, the effect sizes were homogeneous, as reflected by the fact that the null hypothesis of homogeneity in the $Q$ test was not rejected in each dimension. However, for age and sex variables, the effect sizes were more heterogeneous than expected since statistically significant $Q$ values $(p<.05)$ were obtained in each dimension. For these variables, the level of heterogeneity was medium in the MBI dimensions as shown by the $I^{2}$ indexes (minimum $=46.9 \%$, maximum $=69.8 \%$ ). These results indicated the need to find moderator variables that could explain the variability of correlation coefficients for age and sex.

\section{Analysis of moderator variables.}

The final purpose of a meta-analytic study is to test various moderator variables in order to explain the observed heterogeneity. In regards to the correlation between EE and age, none of the moderator variables were found to be significant as an explanation of the variability in effect sizes. As for the correlation between EE and sex, the only significant substantive moderator was marital status $(p=.022)$. Significant methodological moderators were sample size $(p<.001)$, design $(p=.032)$ and sampling method $(p=.018)$. The only significant extrinsic moderator was location $(p=.016$ ) (see Tables 1 and 2).

Table 1. Simple weighted regression analyses of significant moderator variables on the $\mathrm{r}$ index for sex in Emotional Exhaustion.

\begin{tabular}{lccccc}
\hline Moderator variables & $k$ & $b$ & $Q_{\mathrm{R}}$ & $Q_{\mathrm{E}}$ & $\mathrm{R}^{2}$ \\
\hline Sample size & 31 & 0.000 & $29.99^{* * *}$ & 27.95 & .90 \\
Marital status & 14 & 0.003 & $6.81^{*}$ & 20.77 & .64 \\
\hline
\end{tabular}

Note. k: number of studies; $b$ : unstandardized regression coefficient; $Q_{\mathrm{R}}:$ statistical test of between group effects; $Q_{\mathrm{E}}$ : statistical test of homogeneity of the effect size within each group; $R^{2}=$ Proportion of total between-study variance explained; $*: p<.05 ; * * *: p<.001$.

Table 2. One-way analysis of variance of significant moderator variables on the effect size for sex in Emotional Exhaustion.

\begin{tabular}{|c|c|c|c|c|c|}
\hline Moderator variable & $k$ & $r$ & 95\% C. I. & ANOVA results & $R^{2}$ \\
\hline Location & & & & $\mathrm{Q}_{\mathrm{B}}(3)=4.08^{*}$ & .45 \\
\hline North America & 14 & -.056 & {$[-.095,-.017]$} & $\mathrm{Q}_{\mathrm{W}}(27)=38.72$ & \\
\hline Europe & 14 & -.006 & {$[-.031, .020]$} & & \\
\hline Africa & 1 & -.191 & {$[-.322,-.061]$} & & \\
\hline Australia & 2 & -.003 & {$[-.082, .075]$} & & \\
\hline Sampling method & & & & $\mathrm{Q}_{\mathrm{B}}(1)=6.31^{*}$ & .32 \\
\hline Probabilistic & 9 & -.068 & {$[-.108,-.027]$} & $\mathrm{Qw}_{\mathrm{w}}(29)=46.02 *$ & \\
\hline Non probabilistic & 22 & -.009 & {$[-.034, .016]$} & & \\
\hline \multicolumn{6}{|l|}{ Design } \\
\hline Surveys & 7 & -.092 & {$[-.146,-.039]$} & $\mathrm{Q}_{\mathrm{B}}(2)=3.89 *$ & 28 \\
\hline Ex post facto & 23 & .014 & {$[-.038, .010]$} & $\mathrm{Qw}_{\mathrm{w}}(28)=45.81 *$ & \\
\hline Quasi-Experimental & 1 & .004 & {$[-.104, .113]$} & & \\
\hline
\end{tabular}

Regarding the correlation between $\mathrm{D}$ and age, two substantive moderators were significant: rank $(p=.035)$ and the $\mathrm{SD}$ of professional experience $(p=.014)$. In contrast, none of the methodological neither extrinsic moderators were found to be significant. In reference to the correlation between $\mathrm{D}$ and sex, the only statistically significant variable was the extrinsic moderator year $(p=.023)$ (see Table 3).
In the correlation between PA and age, none of the moderator variables were statistically significant. In the correlation between PA and sex, the two significant moderator were the SD of professional experience $(p=.033)$ and sample size $(p<.001)$ (see Table 4$)$. 
Table 3. Simple weighted regression analyses of significant continuous moderator variables on the $\mathrm{r}$ index for age and sex in Depersonalisation.

\begin{tabular}{lllllll}
\hline Variable/ Moderator variable & $k$ & $b$ & $Q_{\mathrm{R}}$ & $Q_{\mathrm{E}}$ & $R^{2}$ \\
\hline Age & & & & & & \\
\hline Rank & 5 & 0.003 & $13.35^{*}$ & 0.97 & .99 \\
SD of professional experience & 6 & 0.078 & $17.59^{*}$ & 2.11 & .99 \\
\hline Sex & & & & & & \\
\hline Year & 14 & 0.007 & $6.02^{*}$ & $56.21^{* * *}$ & .43 \\
\hline
\end{tabular}

Note. k: number of studies; $b$ : unstandardized regression coefficient; $Q_{\mathrm{R}}$ : statistical test of between group effects; $Q_{\mathrm{E}}$ : statistical test of homogeneity of the effect size within each group; $\mathrm{R}^{2}=$ Proportion of total between-study variance explained; $*: p<.05 ; p<.001$

Table 4. Simple weighted regression analyses of significant continuous moderator variables on the $\mathrm{r}$ index for sex in Personal Accomplishment.

\begin{tabular}{lccccc}
\hline Moderator variable & $k$ & $b$ & $Q_{\mathrm{R}}$ & $Q_{\mathrm{E}}$ & $R^{2}$ \\
\hline Sample size & 21 & -0.000 & $9.53^{* *}$ & $46.65^{* * *}$ & .42
\end{tabular}

$\begin{array}{lrrrrr}\text { SD professional experience } & 8 & -0.056 & 7.267 * & 8.76 & .71\end{array}$

Note. $k$ : number of studies; $b$ : unstandardized regression coefficient; $Q_{\mathrm{R}}$ : statistical test of between group effects; $Q_{\mathrm{E}}$ : statistical test of homogeneity of the effect size within each group; $R^{2}=$ Proportion of total between-study variance explained; *: $p<.05, * *: p<.01 * * *: p<.001$.

Finally, multiple regression analysis were used to obtain explanatory models of effect size variation in those relations between some of the burnout dimensions and the moderating variables that were statistically significant in the previous analysis (Sánchez-Meca \& Botella, 2010). In order to test the effect of substantive variables on mean correlations controlling for methodological and extrinsic variables, a forward stepwise procedure was followed. Thus, methodological or extrinsic moderators were introduced into a first block, and the substantive moderators were then introduced into a second block. Differences among the methodological and the substantive blocks were tested trough analysis of variance. This analysis was performed only in those cases where the number of studies was sufficient to permit the application of statistical techniques.

A hierarchical regression model was thus obtained that predicted the variability of effect sizes in the correlation between EE and sex. In this case, the predictor variables were marital status and sample size. The model was significant $\left[Q_{\mathrm{M}}(2)=16.57, p<.001, \mathrm{R}^{2}=.99, k=14\right]$, yielding marital status a significant increment in the explained variance of the model $\left(F(1,11)=5.51, p=.039, \Delta R^{2}=.12\right)$. In the correlation between PA and sex, a model was also formulated. In this case, the predictor variables were standard deviation of professional experience and sample size. It was also significant $\left[Q_{\mathrm{M}}(2)=15.79, p=.007, R^{2}=.99\right]$, although the substantive variable did not reach the statistical significance.

\section{Discussion}

The main objective of this meta-analysis was to calculate the central tendency of the correlations between the three MBI dimensions and a set of socio-demographic variables that can potentially lead to the development of burnout syndrome in police officers. The results obtained in our study showed that younger police officers were slightly more prone to depersonalization than older officers. Female officers were slightly more susceptible to emotional exhaustion. Officers in a sentimental relationship tended to feel more emotionally exhausted, but they had a greater sense of personal achievement. Finally, there were no significant differences between officers with more or less children.

Based on the results of this study, these four sociodemographic variables can be dismissed as risk factors for burnout syndrome in police officers since the mean effect sizes were small (Cohen, 1988). The generalization of these results depends on the statistical model used in the analysis. More specifically, in the case of marital status and number of children, the number of studies was too small to generalize the results. However, in the case of the age and sex, the results can be extended to the population since a randomeffects model was used (Card, 2012).

The influence of different moderator variables was analyzed in age and sex variables because of medium level of heterogeneity of the correlations (Higgins \& Thompson, 2002). The correlation between EE and sex was moderated by marital status, which became higher as the percentage of subjects with a partner increased. This result indicates that being in a relationship can protect male officers from emotional exhaustion. Nevertheless, in the case of female officers, it constitutes a risk factor (Maslach, Schaufeli \& Leiter, 2001). As previously mentioned by other authors (Durán, Montalbán \& Stangeland, 2006), working women are also usually responsible for household tasks and so this result reflects the evident difficulty of reconciling home and family obligations with those at the workplace.

Of the methodological moderators, sample size moderated the correlation between EE and sex. This means that the larger the sample size, the higher the correlation. In addition, this correlation was also moderated by the sampling method. More specifically, in those studies based on probability sampling, the correlations were negative and significant, whereas in those that used non-probability sampling, the correlations were non-significant. The location where the research was carried out was the only significant extrinsic moderator. The fact that only one study was performed in Africa (Wiese, 2002) produced the greatest difference in regards to the mean correlation. Of these variables, sample size and marital status were relevant to the multivariate analysis since they explained much of the variability of the effect sizes of the correlation between EE and sex.

The correlation between $\mathrm{D}$ and age was moderated by the rank of police officers and the standard deviation of professional experience. In this sense, the correlation became higher as the percentage of officers of the lowest rank increased. This result is in consonance with the idea that novice police officers are exposed to a wide range of potential stressors (Backteman-Erlanson et al., 2012). In the case of SD of professional experience, the correlation became stronger as the variability increased.

The correlation between $\mathrm{D}$ and sex was moderated only by the extrinsic moderator year of article publication. This 
correlation was stronger as the articles were published more recently. Hence, it is more likely to find higher correlation among $\mathrm{D}$ and sex in articles published recently than in past years.

Finally, the moderators of the correlation between PA and sex were the standard deviation of professional experience and sample size. In this case, as the variability in professional experience and sample size decreased, the correlation was higher.

The analysis of moderators shows that marital status and police rank may have an indirect impact on the appearance of the burnout syndrome. Accordingly, they can act as moderators of the correlations between sex and emotional exhaustion, in the first case, and between age and depersonalization, in the second case. In other words, being in a relationship and belonging to the lowest rank may contribute in different ways to the development of the burnout symptoms, depending on sex and age. This risk profile is similar to that found in other research studies (Adebayo et al., 2008).

Moreover, the correlations between MBI dimensions and age and sex can vary depending on methodological variables such as sample size, sampling method, research design, variability of variables, and location where the study were conducted. These results confirm those found in other studies, which indicate that with the MBI, different conclusions can be obtained, depending on these methodological variables (e.g., Aguayo, Vargas, De la Fuente \& Lozano 2011; Vargas, Cañadas, Aguayo, Fernández \& De la Fuente, 2014).

Our research has also led to a series of reflections on the nature and difficulties that can arise in meta-analytical research. Firstly, certain limitations should be taken into account when interpreting the results of this study. On the one hand, the results pertaining to the correlation between MBI dimensions and marital status and number of children were obtained with a fixed-effects model and thus cannot be generalized. On the other hand, some of the variables included in the analysis of moderators only appeared in a few of the studies. For this reason, the results of the moderator analyses with a small number of studies should be regarded as tentative, pending the appearance of new publications with more information on the topic. This is especially important to consider in relation to some variables, such as work type, shift, and rank that may lead to different burnout levels depending on the degree of danger which police officers have to face.

\section{References}

References with an asterisk have been included in the meta-analysis.

*Adebayo, D. O., Sunmola, A. M., \& Udegbe, I. B. (2008). Workplace fairness and emotional exhaustion in Nigeria police: The moderating role of gender. Anxiety, Stress, \& Coping, 21(4), 405-416. doi: 10.1080/10615800701415456

Aguayo, R., Vargas, C., De la Fuente, E. I., \& Lozano, L. M. (2011). A metaanalytic reliability generalization study of the Maslach Burnout Invento-
Secondly, in this field, there is a certain scarcity of usable data. Despite the number of studies that focus on sociodemographic variables in relation to burnout syndrome, all too often, these studies do not include any descriptive statistical data. This makes it impossible to calculate the effect size of the correlation between socio-demographic variables and burnout dimensions. For example, it was found that over half of the studies in our meta-analysis lacked this type of information. Unfortunately, this perpetuates the reigning confusion concerning socio-demographic variables and their possible status as risk factors of burnout syndrome.

An interesting question would be whether researchers and journal editors could work together to promote the inclusion of this type of data. Although the analysis of publication bias indicated that this is not a serious threat to the validity of the results of our study, a wider access to statistical information would have greatly facilitated and enhanced the results of our research. In this sense, there are several tools (e.g. websites created by educational institutions, research groups, and authors) that disseminate information and which are not subject to the restrictions of space in scientific journals.

Thirdly, when performing a meta-analysis on burnout syndrome, there are certain methodological moderators (e.g., sample size, sampling method, research design, variability of scores) that, against all logic, seem to be the source of heterogeneity in this area and which could also be those that are responsible for prolonging the ongoing controversy regarding the results in this field. It would be desirable to pay greater attention to those methodological aspects that tend to generate "noise" when studying relevant effect sizes.

Finally, sex and particularly age do not appear to be risk factors for burnout syndrome in police officers. Possibly, the nature of police work and the stressors that officers (especially those of the lowest rank) face in daily work cause that the socio-demographic factors be irrelevant to the development of burnout. In this sense, future research should explore the relations between burnout dimensions and work conditions, such as officer unit, rank, job seniority, professional experience, and shift type. It would be also necessary to analyze the differences in police officers from different countries since the stressors they have to face could vary substantially, although the scarcity of primary studies may be problematic.

Acknowledgements.- This work was funded by the Excellence Research Projects P07HUM-02529 and P11HUM- 7771 (Junta de Andalucía-Spain).

ry. International Journal of Clinical and Health Psychology, 11(2), 343-361. Retrieved from http://www.aepc.es/ijchp/articulos_pdf/ijchp-383.pdf

*Alcorn, D., \& Petrie, S. (1997). Police Burnout and Attitudes to Women and Domestic Violence. Unpublished manuscript. Retrieved from http://www.aic.gov.au/media_library/conferences/policewomen2/alc orn.pdf 
*Anderson, E. M. (1994). Stress and its correlates: An empirical investigation among North Dakota peace officers. Doctoral Dissertation. Aranda, C., \& Pando, M. (2010). Edad, síndrome de agotamiento profesional (burnout), apoyo social y autoestima en agentes de tránsito, México. Revista Colombiana de Psiquiatría, 39(3), 510-522. doi:10.1016/S0034-7450(14)60222-5

Aranda, C., \& Pando, M. (2010). Edad, síndrome de agotamiento profesional (burnout), apoyo social y autoestima en agentes de tránsito, México. Revista Colombiana de Psiquiatría, 39(3), 510-522.

Ato, M., López, J. J., \& Benavente, A. (2013). Un sistema de clasificación de los diseños de investigación en psicología. Anales de Psicologia, 29(3), 1038-1059. doi: 10.6018/analesps.29.3.178511

*Backteman-Erlanson, S., Padyab, M., \& Brulin, C. (2013). Prevalence of burnout and associations with psychosocial work environment, physical strain, and stress of conscience among Swedish female and male police personnel. Police Practice and Research, 14(6), 491-505. doi: 10.1080/15614263.2012.736719

*Bakker, A. B., van Emmerik, H., \& Euwema, M. C. (2006). Crossover of burnout and engagement in work teams. Work and Occupations, 33(4), 464-489. doi:10.1177/0730888406291310

*Baruch-Feldman, C., Brondolo, E., Ben-Dayan, D., \& Schwartz, J. (2002). Sources of social support and burnout, job satisfaction, and productivity. Journal of Occupational Health Psychology, $7(1), \quad 84 \quad-93$. doi:10.1037//1076-8998.7.1.84

*Berg, A. M., Hem, E., Lau, B., \& Ekeberg, Ø. (2006). An exploration of job stress and health in the Norwegian police service: A cross sectional study. Journal of Occupational Medicine and Toxicology, 1, 26. doi:10.1186/1745-6673-1-26

*Blumenstein, L., Fridell, L., \& Jones, S. (2012). The link between traditional police sub-culture and police intimate partner violence. Policing: An International Journal of Police Strategies \& Management, 35(1), 147-164. doi:10.1108/13639511211215496

Borenstein, M., Hedges, L. V., Higgins, J. P. T., \& Rothstein, H. R. (2014). Comprehensive Meta-analysis Version 3. Englewood, NJ: Biostat.

*Briones, D., \& Boutin, A. P. K. (2013). Burnout and Coping Strategies in Male Staff from National Police in Valpara? So, Chile. Iranian Journal of Public Health, 42(9), 950-959. Retrieved from http://search.proquest.com/docview/1462030817/fulltextPDF?accou ntid $=14542$

*Burke, R. J., \& Mikkelsen, A. (2005). Burnout, job stress and attitudes towards the use of force by Norwegian police officers. Policing: An International Journal of Police Strategies \& Management, 28(2), 269-278. doi: 10.1108/13639510510597906

*Burke, R. J., Richardsen, A. M., \& Martinussen, M. (2006). Gender differences in policing: Reasons for optimism? Policing: An International Journal of Police Strategies and Management, 29(3), 513-523. doi:10.1108/13639510610684737

Card, N. A. (2012). Applied meta-analysis for social science research. New York, NY: Guilford Press.

*Chrisopoulos, S., Dollard, M. F., Winefield, A. H., \& Dormann, C. (2010). Increasing the probability of finding an interaction in work stress research: A two-wave longitudinal test of the triple-match principle. Journal of Occupational and Organizational Psychology, 83(1), 17-37. doi: 10.1348/096317909X474173

Cohen, J. (1988). Statistical power analysis for the behavioral sciences (2nd ed.). New Jersey, NJ: Lawrence Erlbaum.

*Colegrove, S. C. B. (1983). Personality and demographic characteristics as predictors of burnout in female police officers. (Doctoral Dissertation, California School of Professional Psychology). Available from Proquest Dissertations and Theses. (UMI No. 8317074).

Cooper, H., Hedges, L. V., \& Valentine, J. C. (2009). The handbook of research synthesis and meta-analysis (2nd ed.). New York, NY: Russell Sage Foundation.

*Crassweller, P. L. (1995). Relationships among occupational stressors, social supports, and burnout for prairie urban police officers. (Doctoral Dissertation, University of Regina, Canada). Available from Proquest Dissertations and Theses. (UMI No. MM01215).

*De Haas, S., Timmerman, G., \& Höing, M. (2009). Sexual harassment and health among male and female police officers. Journal of Occupational Health Psychology, 14(4), 390-401. doi:10.1037/a0017046
*De la Fuente Solana, E. I., Aguayo, R., Pecino, C. V., \& de la Fuente, G. C. (2013). Prevalence and risk factors of burnout syndrome among Spanish police officers. Psicothema, 25(4), 488-493. doi: 10.7334/psicothema2013.81

De la Fuente, E. I., Lozano, L. M., García-Cueto, E., San Luis, C., Vargas, C., Cañadas, G. R., ... Hambleton, R. K. (2013). Development and validation of the Granada Burnout Questionnaire in Spanish police. International Journal of Clinical and Health Psychology, 13(3), 216-225. doi:10.1016/S1697-2600(13)70026-7

*Durán, M. A., Montalbán, F. M., \& Stangeland, P. (2006). El síndrome de estar quemado en la policía: perfil de incidencia e influencia de factores socio-demográficos. Revista de psicología social, 21(1), 95-107. doi: 10.1174/021347406775322205

*Dutton, J. D. (2005). Police officer stress, burnout, and substance abuse: A crossectional view of officers working in mid-sized Alabama police departments. . (Doctoral Dissertation, Capella University). Available from Proquest Dissertations and Theses. (UMI No. 3178461).

*Fontes, F. (2011). Burnout e bem-estar no trabalbo: estudo exploratório na Divisão da Polícia de Segurança Pública de Portimão. (Doctoral Dissertation, Universidade do Algarve, Portugal). Retrieved from https://sapientia.ualg.pt/bitstream/10400.1/1487/2/Tese $\% 20 \mathrm{de} \% 20$ Mestrado.pdf

*Gaines, J., \& Jermier, J. M. (1983). Emotional exhaustion in a high stress organization. Academy of Management Journal, 26(4), 567-586.

*Gil-Monte, P. R. (2005). Influencia en la calidad de las relaciones interpersonales en el contexto laboral sobre el síndrome de agotamiento profesional o del quemado (Burnout). Anuari de Psicologia de la Societat Valenciana de Psicologia, 10(2), 25-40.

*Gonçalo, H., Gomes, A. R., Barbosa, F., \& Afonso, J. (2010). Stresse ocupacional em forças de segurança: Um estudo comparativo. Análise Psicológica, 28(1), 165-178.

*Grawitch, M. J., Barber, L. K., \& Kruger, M. H. (2010). Role identification, community socio-economic status demands, and stress outcomes in police officers. Anxiety, Stress, and Coping, 23(2), 165-180. doi:10.1080/10615800902935542

Halbesleben, J. R. B., \& Demerouti, E. (2005). The construct validity of an alternative measure of burnout: Investigating the English translation of the Oldenburg Burnout Inventory. Work \& Stress,19(3), 208-220. doi: $10.1080 / 02678370500340728$

*Hawkins, H. C. (2001). Police officer burnout: A partial replication of Maslach's Burnout Inventory. Police Quarterly, 4(3), 343-360. doi:10.1177/109861101129197888

Higgins, J. P. T., \&Thompson, S. G. (2002). Quantifying heterogeneity in a meta-analysis. Statistics in Medicine, 21, 1539-1558. doi:10.1002/sim.1186

Huedo-Medina, T. B., Sánchez-Meca, J., Marín-Martínez, F., \& Botella, J. (2006). Assessing heterogeneity in meta-analysis: Q statistic or I2 index? Psychological Methods, 11(2), 193-206. doi:10.1037/1082-989X.11.2.193

*Jermier, J. M., Gaines, J., \& Nancy, J. M. (1989). Reactions to physically dangerous work: A conceptual and empirical analysis. Journal of Organizational Behavior, 10, 15-33.

*Kop, N., \& Euwema, M. C. (2001). Occupational stress and the use of force by Dutch police officers. Criminal Justice and Behavior, 28(5), 631652. doi:10.1177/009385480102800505

*Kop, Nicolien, Euwema, M., \& Schaufeli, W. (1999). Burnout, job stress and violent behaviour among Dutch police officers. Work and Stress, 13(4), 326-340. doi:10.1080/02678379950019789

Kristensen, T. S., Borritz, M., Villadsen, E., \& Christensen, K. B. (2005). The Copenhagen Burnout Inventory: A new tool for the assessment of burnout. Work \& Stress,19(3), 192-207. doi: 10.1080/02678370500297720

Leiter, M. P., Bakker, A. B., \& Maslach, C. (2014). Burnout at work. A Psychological Perspective. Psychology Press

*Martinussen, M., Richardsen, A. M., \& Burke, R. J. (2007). Job demands, job resources, and burnout among police officers. Journal of Criminal Justice, 35(3), 239-249. doi:10.1016/j.jcrimjus.2007.03.001

Maslach, C., \& Jackson, S. E. (1981). The measurement of experienced burnout. Journal of Organizational Behavior, 2, 99-113. Retrieved from http://www.aagbi.org/sites/default/files/Maslach.pdf

Maslach, C., Schaufeli, W. B., \& Leiter, M. P. (2001). Job burnout. Annual Review of Psychology, 52, 397-422. doi:10.1146/annurev.psych.52.1.397 
*McCarty, W. P. (2013). Gender differences in burnout among municipal police sergeants. Policing: An International Journal of Police Strategies \& Management, 36(4), 803-818.

McCarty, W. P., Zhao, J. S., \& Garland, B. E. (2007). Occupational stress and burnout between male and female police officers. Are there any gender differences? Policing: An International Journal of Police Strategies and Management, 30(4), 672-691. doi:10.110813639510710833938

Moher, D., Shamseer, L., Clarke, M., Ghersi, D., Liberati, A., Petticrew, M., ... \& Stewart, L. A. (2015). Preferred reporting items for systematic review and meta-analysis protocols (PRISMA-P) 2015 statement. Systematic Reviews, 4(1), 1. doi: 10.1186/2046-4053-4-1

*Pita, M. E. (1993). Stress and burnout in police officers (Doctoral Dissertation, The George Washington University). Available from Proquest Dissertations and Theses. (UMI No. 9316122).

*Queirós, C., Da Silva, A. L., \& Vara, N. (2012). Un estudio comparativo de burnout en policías y bomberos portugueses. In IX Congreso Internacional de la Sociedad Española para el estudio de la Ansiedad y el Estrés (Vol. 2). Valencia, Spain.

*Queirós, C., Kaiseler, M., \& da Silva, A. L. (2013). Burnout as a predictor of aggressivity among police officers. European Journal of policing Studies, 1(2), 110-135.

*Richardsen, A. M., Burke, R. J., \& Martinussen, M. (2006). Work and health outcomes among police officers: The mediating role of police cynicism and engagement. International Journal of Stress Management, 13(4), 555-574. doi:10.1037/1072-5245.13.4.555

*Rogers, M. K. (1995). Understanding resistance to police burnout: a salutogenic approach. Doctoral Dissertation. Available from Proquest Dissertations and Theses. (UMI No. 0625).

Rosenthal, R. (1991). Meta-analytic procedures for social research (2nd ed.). Newbury Park, CA: Sage.

Salazar, A. (2015). Salud, burnout y estrés en ámbitos laborales. Una revisión sistemática. Psicología y Salud, 25(2), 147-155. Retrieved from http://revistas.uv.mx/index.php/psicysalud/article/view/1815/3297

Sánchez-Meca, J., \& Botella, J. (2010). Revisiones sistemáticas y metaanálisis: Herramientas para la práctica profesional. Papeles del Psicólogo, 31(1), 7-17. Retrieved from http://www.papelesdelpsicologo.es/pdf/1792.pdf

*Sánchez-Nieto, J. M. (2012). Frecuencia del burnout en policías de la Ciudad de México. Liberabit. Revista de Psicología, 18(1), 69-74.

*Schaible, L. M., \& Gecas, V. (2010). The impact of emotional labor and value dissonance on burnout among police officers. Police Quarterly, 13(3), 316-341. doi:10.1177/1098611110373997

Schaufeli, W. B., \& Enzmann, D. (1998). The burnout companion to study and practice: $A$ critical anylysis. London: Tylor and Francis.

Schaufeli, W. B., Leiter, M. P., \& Maslach, C. (2009). Burnout: 35 years of research and practice. Career Development International, 14(3), 204-220. doi:10.1108/13620430910966406
*Stearns, G. M., \& Moore, R. J. (1990). Job burnout in the Royal Canadian Mounted Police: Preliminary findings from a Saskatchewan sample. Journal of Police Science and Administration, 17(3), 183-193.

*Stearns, G. M., \& Moore, R. J. (1993). The physical and psychological correlates of job burnout in the Royal Canadian Mounted Police. Canadian Journal of Criminology, 35, 127-148.

*Taris, T. W., Kompier, M. A. J., Geurts, S. A. E., Houtman, I. L. D., \& van den Heuvel, F. F. M. (2010). Professional efficacy, exhaustion, and work characteristics among police officers: A longitudinal test of the learning-related predictions of the demand-control model. Journal of $\mathrm{Oc}$ cupational and Organizational Psychology, 83(2), 455-474. doi:10.1348/096317909X424583

*Van der Velden, P. G., Kleber, R. J., Grievink, L., \& Yzermans, J. C. (2010). Confrontations with aggression and mental health problems in police officers: The role of organizational stressors, life-events and previous mental health problems. Psychological Trauma: Theory, Research, Practice, and Policy, 2(2), 135-144. doi: 10.1037/a0019158

*Van Emmerik, I. J. H., Bakker, A. B., \& Euwema, M. C. (2008). What happens after the developmental assessment center?: Employees' reactions to unfavorable performance feedback. Journal of Management Development 27(5), 513-527. doi:10.1108/02621710810871826

Vargas, C., Cañadas, G. A., Aguayo, R., Fernández, R, \& De la Fuente, E. I. (2014). Which occupational risk factors are associated with burnout in nursing? A meta-analytic study. International Journal of Clinical and Health Psychology, 14(1), 28-38. Retrieved from http://www.elsevier.es/enrevista-international-journal-of-clinical-and-355-articulo-whichoccupational-risk-factors-are-90260035

Viechtbauer, W. (2010). Conducting meta-analyses in R with the metafor package. Journal of Statistical Software, 36(3). Retrieved from http://brieger.esalq.usp.br/CRAN/web/packages/metafor/vignettes/ metafor.pdf

Vuorensyrjä, M., \& Mälkiä, M. (2011). Nonlinearity of the effects of police stressors on police officer burnout. Policing: An International Journal of Police Strategies and Management, 34(3), 382-402. doi:10.1108/13639511111157474

*Wiese, L. (2002). Coping, stress, burnout and engagement within the South African police service in Kwazulu-Natal. Doctoral Dissertation. Retrieved from North-West University Institutional Repository.

*Willis, T. A., O'Connor, D. B., \& Smith, L. (2008). 'Investigating effortreward imbalance and work-family conflict in relation to morningnesseveningness and shift work. Work \& Stress, 22(2), 125-137. doi: 10.1080/02678370802180558

Worley, J. A., Vassar, M., Wheeler, D. L., \& Barnes, L. L. (2008). Factor Structure of Scores From the Maslach Burnout Inventory A Review and Meta-Analysis of 45 Exploratory and Confirmatory Factor-Analytic Studies. Educational and Psychological Measurement, 68(5), 797-823.

(Article received: 05-06-2016; revised: 07-09-2016; accepted: 16-09-2016) 